\title{
TENDINOPATIA DO TENDÃO CALCÂNEO
}

\section{TENDINOPATHIES OF THE TENDON CALCANEUS}

\author{
Fabricio Furtado Vieira ${ }^{1}$, Wagner Menna Pereira ${ }^{2}$, \\ Luiz Alfredo Braun Ferreira ${ }^{3}$, Luciano Pavan Rossi ${ }^{4}$ \\ ${ }^{1}$ Fisioterapeuta, mestrando em Fisiologia pela Universidade Federal do Paraná (UFPR). \\ E-mail: fabriciofurvi@yahoo.com.br \\ ${ }^{2}$ Docente da Universidade Estadual do Centro-Oeste (UNICENTRO-PR). \\ ${ }^{3}$ Docente da Universidade Estadual do Centro-Oeste (UNICENTRO-PR). \\ ${ }^{4}$ Docente da Universidade Estadual do Centro-Oeste (UNICENTRO-PR).
}

Recebido para publicação em: 03/03/2010

Aceito para publicação em: 15/05/2010

\section{RESUMO}

Tendões são estruturas formadas por um tecido conjuntivo fibroso denso e regular que ligam os músculos esqueléticos aos ossos. Devido a grande controvérsia a respeito das tendinopatias, esse artigo tem como objetivo realizar um levantamento bibliográfico a respeito das alterações histopatológicas, tratamento fisioterapêutico, mecanismo da dor, quadro clínico, incidência e etiologia nas tendinopatias do tendão calcâneo. A literatura mostra que as tendinopatias, em particular as tendinoses, se caracterizam por uma degeneração do colágeno e ausência de inflamação, sem evidências substanciais que apóiem a existência da tendinite. Microscopicamente a tendinose, caracteriza-se por processo degenerativo com aumento do número de fibroblastos, hiperplasia vascular, desorganização do colágeno e aumento da matriz extracelular. Em recentes pesquisas, substâncias químicas foram encontradas em excesso em pacientes com tendinopatia e são consideradas como as possíveis responsáveis pela dor, como a substância $\mathrm{P}$ e o glutamato. Acredita-se que a etiologia das tendinopatias seja uma combinação multifatorial de fatores extrínsecos e intrínsecos. Dentre as diversas formas de tratamento encontradas na literatura, o treinamento excêntrico vem ganhando evidência, em estudos clínicos randomizados, como uma forma efetiva de tratamento e de baixo custo.

Palavras-chave: Tendinopatia. Tendinose. Fisioterapia. Histopatologia.

\begin{abstract}
Tendons are structures formed by a dense and regular fibrous conjunctive tissue that link the skeletal muscles to the bones. Due to great controversy regarding the tendinopathies, that this article has like objective bibliographic review rising regarding the alterations histopathologics, physiotherapy treatment, mechanism
\end{abstract}


of pain, clinical features, incidence and aetiology in the tendinopathies of the calcaneus. The literature shows that the tendinopathies, specially the tendinosis, are characterized by a collagen degeneration and inflammation absence, without substantial evidences that support the existence of the tendinitis. Macroscopically the tendinosis, is characterized by degenerative process with increase the number of fibroblasts, vascular hiperplasia, disorganise of the collagen and increase of the extracellular matrix. In recent researches, chemical substances were found in excess in patients with tendinopatia and they are considered as the possible responsible by the pain, as substance P and glutamate. It is believed that the aetiology of the tendinopathies is a combination multifactorial of extrinsic and intrinsic factors. Among the several treatment forms found in the literature, the eccentric training comes giving evidence, in randomized clinical studies, as an effective form of treatment and of low cost.

Keywords: Tendinopathy. Tendinosis. Physiotherapy. Histopathology.

\section{Introdução}

Os tendões são formados por um tecido conjuntivo fibroso denso e regular, no qual os feixes de colágenos apresentam uma orientação paralela, cuja direção é devida às trações impostas em um determinado sentido. Os tendões são estruturas que ligam os músculos esqueléticos aos ossos, permitindo dessa forma o movimento das articulações ou a manutenção da postura do corpo (JUNQUEIRA; CARNEIRO, 1990; NORDIN; FANKEL, 2003; WHITING; ZERNICKE, 2001).

Os tendões têm uma vascularização limitada que afeta diretamente seu processo de cura, recebendo seu suprimento sanguíneo diretamente de vasos do perimísio, periósteo e por meio de vasos no paratendão. Estudos em humanos e animais demonstraram uma variedade de terminações nervosas e de receptores mecânicos, com funções nociceptivas e proprioceptivas (NORDIN; FANKEL, 2003).

O tendão é formado principalmente por fibras colágenas do tipo I e pequenas quantidades de fibras elásticas, apresentando uma baixa capacidade de alongamento (WHITING; ZERNICKE, 2001). Um tendão normal pode aguentar uma carga de 50 a $100 \mathrm{~N} / \mathrm{m}^{2}$, e pode ser estirado a aproximadamente $4 \%$ de seu comprimento total antes de evidências microscópicas de ruptura de algumas fibras de colágeno. (MAFFULLI; BENAZZO, 2000).

A literatura mostra que as tendinopatias, em particular as tendinoses, se caracterizam por uma degeneração do colágeno e ausência de inflama- ção, concluindo-se então que não há evidências substanciais que apoiem a existência da tendinite. Estudos demonstram rupturas na arquitetura normal das fibras colágenas e crescimento de fibroblastos. Demonstraram que as microrupturas são acompanhadas de cicatrização parcial e de hiperplasia angiofibroblástica. (LEON, 2006; SHARMA; MAFFULLI. 2005; KHAN; COOK, 2000; FILHO; COHEN, 2004).

Devido à grande controvérsia a respeito do assunto, este artigo tem como objetivo realizar um levantamento bibliográfico a respeito das alterações histopatológicas, tratamento fisioterapêutico, mecanismo da dor, quadro clínico, incidência e etiologia nas tendinopatias do tendão calcâneo, proporcionando assim um tratamento mais direcionado às alterações encontradas nas tendinopatias.

\section{Materiais e métodos}

Para este estudo de revisão bibliográfica, foram realizados levantamentos bibliográficos na biblioteca da Universidade Estadual do Centro-Oeste (UNICENTRO), em revistas indexadas e sites como Bireme, Pubmed, Lilacs e Cochrane. Foram utilizados para a pesquisa na internet os seguintes descritores: tendinose, tendinopatia, tendinopathy, tendinosis, treinamento excêntrico, eccentric training, etiology e tendon pain. 


\section{Resultados e discussão}

\subsection{Incidência}

As patologias do tendão calcâneo se relacionam, em aproximadamente $70 \%$ das vezes, com algum tipo de atividade esportiva; dessas, 90\% ocorrem em corredores (AMATUZZI; CARAZZATO, 2004).

A ocorrência da tendinopatia do calcâneo é mais alta entre indivíduos que participam de corridas de médias e longas distâncias, tênis, badminton, voleibol e futebol. Uma incidência anual de desordens do tendão calcâneo, entre corredores de alto nível, era de 7\% e 9\%. O diagnóstico clínico mais comum nas desordens do tendão calcâneo foram as tendinopatias (55\% a $66 \%$ ), seguidas de problemas da inserção do tendão (bursite retrocalcânea e tendinopatia insercional) (20\% a $25 \%)$. Mau alinhamento de extremidade inferior foi achado em $60 \%$ dos pacientes com desordem do tendão calcâneo. Sendo essas desordens mais comuns entre atletas mais velhos que em atletas jovens (PAAVOLA et al., 2002).

\subsection{Quadro Clínico}

As lesões crônicas do tendão calcâneo são divididas em tendinopatias não insercionais e insercionais. As observações clínicas nas tendinopatias não insercionais são dor no tendão calcâneo $2 \mathrm{~cm}$ a $6 \mathrm{~cm}$ acima da inserção, correspondendo à zona hipovascular. A dor normalmente acorre após exercícios e é pior pela manhã. Ao exame físico revela espessamento do tendão e dor à palpação. A dor é exacerbada pela flexão plantar sob apoio. Pode-se observar crepitação à palpação (AMATUZZI; CARAZZATO, 2004).

Regiões de degeneração de tendão apresentam aumento no sinal na imagem de ressonância magnética e regiões hipoecóicas no ultra-som. Esse fenômeno parece corresponder à região de degeneração mucóide (KHAN; COOK, 2000; KHAN et al., 1999).

Paratendinite acontece onde um tendão sofre atrito sobre uma protuberância óssea. É caracteri- zada clinicamente por edema agudo e hiperemia do paratendão com infiltração de células inflamatórias. Após algumas horas ou dias, exsudato fibrinoso envolve o tendão e causa crepitação e espessamento que podem ser observados ao exame clínico (KHAN et al., 1999).

\subsection{Etiologia}

A teoria mecânica das lesões tendíneas por overuse propõe que, quando um tendão é repetidamente estirado numa proporção de $4 \%$ a $8 \%$ de seu comprimento, torna-se incapaz de suportar tensão adicional, ocasionando o dano. Ademais, se uma tensão repetitiva continuar sendo imposta ao tendão, não dando tempo para um processo de reparo pelas células do mesmo, o processo de adaptação será subjugado e lesões adicionais ocorrerão (PAAVOLA et al., 2002; KHAN et al., 1999; HALE, 2005).

Parece existir algum consenso quando a maioria dos investigadores afirma que as lesões tendinosas por overuse são multifatoriais e resultam de uma interação entre fatores intrínsecos e extrínsecos (JARDIM, 2005).

Os fatores extrínsecos são aqueles relacionados com as cargas excessivas aplicadas ao corpo, com os erros de treino, ou com o uso de equipamento inadequado (JARDIM, 2005).

Os fatores de risco intrínsecos para a tendinopatia do calcâneo estão relacionados ao pé cavo ou plano, retropé varo ou valgo, assim como desalinhamentos rotacionais e angulares do membro inferior. Existe também uma área de relativa hipovascularização que pode se relacionar com o local mais comum de lesão. Quanto aos fatores de risco extrínsecos, os mais comuns são os erros de treinamento (duração, intensidade e frequência) e do equipamento, tal como calçado inadequado (AMATUZZI; CARAZZATO, 2004).

Os fatores associados às desordens do tendão calcâneo incluem hiperpronação do pé, mobilidade limitada da articulação subtalar e do tornozelo, deformidade em varo, discrepância do comprimento dos membros inferiores. Fraqueza e encurtamento muscular diminuem sua capacidade 
de absorver energia, levando à sobrecarga do tendão (PAAVOLA et al., 2002).

Erros de treinamento também se mostram associados à tendinopatia do tendão calcâneo. A maioria dos erros inclui corridas longas e intensidades altas, aumento exagerado na distância e/ou na intensidade de treinamento, assim como trabalhos monótonos e assimétricos; treinamento especializado e fadiga são fatores adicionais (PAAVOLA et al., 2002).

Outro mecanismo proposto recentemente para o desenvolvimento das tendinopatias é uma mudança no equilíbrio entre metaloproteases e inibidores das metaloproteases. Essas substâncias são responsáveis pelo remodelamento do tecido. Observou-se que as metaloproteases tiveram sua expressão aumentada e seus respectivos inibidores diminuídos, conduzindo ao excesso de degeneração do colágeno em pacientes com tendinopatia. Porém, ainda não está claro se o aumento da expressão das metaloproteases é responsável pelas tendinopatias (BROWN et al., 2006).

\subsection{Histopatologia}

As mudanças, observadas na tendinose, ocorrem no colágeno, tenócitos e também dentro da matriz extracelular. Algumas fibras de colágeno parecem desorientadas, dando a impressão de perda da orientação paralela, há uma diminuição no diâmetro das fibras e uma diminuição na densidade global de colágeno. Também se pode notar um aumento do colágeno tipo III (reparador). Outra característica da tendinose é a proliferação de vasos capilares e arteríolas (KHAN et al., 2000; BENEGAS, 2004; JARDIM, 2005).

Tendinite é o termo tradicionalmente usado para descrever um tendão doloroso crônico e é acompanhado por uma resposta inflamatória. No entanto, as evidências de estudos histopatológicos, bioquímicos e moleculares mostram que a lesão seria mais bem descrita como uma tendinose (RILEY, 2004; JARDIM, 2005).

O exame histopatológico de tendões calcâneo sintomáticos revelou degeneração e desorganiza- ção das fibras de colágeno, bem como aumento na vascularização. Lesões inflamatórias e tecido de granulação não são frequentes e, quando presentes, estão associadas com ruptura parcial (KHAN; COOK, 2000).

Condições como tendinite do calcâneo foram extensamente pesquisadas, embora a infiltração de células inflamatórias no tendão não tenha sido vista em espécimes de biópsia de pacientes com problemas crônicos; os mediadores bioquímicos de inflamação, como as prostaglandinas $\mathrm{E}_{2}$, não foram achados. Entretanto, a ausência de infiltração de células inflamatórias no estado crônico não exclui uma condição inflamatória anterior (PAAVOLA et al., 2002).

Embora não exista nenhuma evidência histopatológica convincente da existência da tendinite, estudos realizados em coelhos demonstraram a presença de células inflamatórias no $5^{\circ}$ dia, decrescendo até o $18^{\circ}$ após tenotomia. Claramente esse modelo não reproduz o mecanismo das tendinopatias por overuse. Porém, enquanto não sejam obtidas biópsias apropriadas em humanos, a possibilidade de um período breve de verdadeira tendinite não pode ser totalmente excluída, pois na prática clínica a maioria das tendinopatias são crônicas quando o paciente busca atenção médica (KHAN et al., 2000; ENWEMEKA, 1989).

\subsection{Mecanismo da dor}

A patogênese básica da dor e degeneração nas tendinopatias é até hoje pobremente entendida, o que acaba limitando o desenvolvimento de intervenções terapêuticas específicas (LIAN et al., 2006).

Classicamente, a dor nas tendinopatias era atribuída a um processo inflamatório, mas, de acordo com as últimas evidências, as tendinopatias são consideradas condições degenerativas e não inflamatórias (JARDIM, 2005).

No modelo de dor mecânica, acredita-se que fibras colágenas intactas são livres de dor e dolorosas quando se rompem, como em um caso de lesão aguda. No entanto, há numerosas observações nas quais os tendões não estão completamente intactos, 
porém permanecem livres de dor. Isso enfatiza que a dor em tendão pode não ser devido a uma relação direta entre separação mecânica de colágeno e dor (KHAN; COOK, 2000).

Estudos recentes demonstram, através de técnicas de microdiálise, altas concentrações de glutamato, um neurotransmissor excitatório, e imunoreação para seu receptor (NMDAR1) na porção média do tendão calcâneo de pacientes com tendinose crônica, em comparação ao grupo controle. Sendo que a liberação dessas substâncias químicas durante o processo degenerativo pode ser um potencial gerador da dor. Contudo, os autores não verificaram níveis aumentados de prostaglandina $\mathrm{E}_{2}$, o que não caracteriza um processo inflamatório (ALFREDSON, 1999).

A análise histológica de tendões dolorosos mostrou um número aumentado de fibras sensoriais para substância $\mathrm{P}$ dentro do próprio tendão em relação ao grupo controle. A Substância P (SP) participa em ações inflamatórias como vasodilatação, extravasamento de plasma, produção de citocinas, além de seu papel na nocicepção devido à estimulação direta dos nociceptores (LIAN et al., 2006; ALFREDSON, 2000).

Foi demonstrado que a substância $\mathrm{P}$ pode estimular proliferação de fibroblastos e células endoteliais, podendo ser uma hipótese para as mudanças morfológicas observadas em pacientes com tendinopatia, como a transformação de tenócitos, hipercelularidade, neovascularização e destruição da matriz do próprio tendão (LIAN et al., 2006).

Tradicionalmente, foi proposta que a dor associada à tendinopatia do calcâneo se desenvolva como resultado da inflamação, separação das fibras de colágeno ou degeneração do tecido. Porém, evidências científicas a respeito desses mecanismos são escassas. Tendões calcâneos não mostraram evidências de qualquer processo inflamatório, assim como muitos tendões com sinais de degeneração não causam dor (KHAN; COOK, 2000; PAAVOLA et al., 2002).

Foi especulado, com algumas evidências científicas, que uma combinação de substâncias bioquímicas nocivas (sulfato de condroitina, glutamato, substância $\mathrm{P}$ ou peptídeo relacionado ao gene da calcitonina) e a neovascularização possam irritar os nociceptores no tendão (KHAN; COOK, 2000; PAAVOLA et al., 2002).

\subsection{Tratamento}

O treinamento excêntrico foi sugerido como uma modalidade de tratamento para o joelho de saltador já em 1984 por Curwin e Stanish. Recentemente, o treinamento excêntrico foi visto como efetivo em estudos piloto em pacientes com tendinopatia patelar, como também em estudos randomizados em pacientes com tendinopatia do calcâneo (BAHR, 2006).

A conduta inicial na tendinopatia do calcâneo consiste geralmente de orientação, repouso, analgésico, injeções de aprotinina, mudanças de calçados, correção de qualquer mau alinhamento, alongamentos e exercícios de fortalecimento excêntricos. A cirurgia é recomendada se o tratamento conservador não obtiver resultados em pelo menos seis meses (SAYANA; MAFFULLI, 2007; ALFREDSON; LORENTZON, 2000). Em geral, o tratamento conservador não tem êxito e o tratamento cirúrgico é indicado em aproximadamente $25 \%$ dos pacientes (ALFREDSON; LORENTZON, 2000).

$\mathrm{O}$ tratamento conservador, na tendinopatia do calcâneo, deveria ser dirigido para aliviar sintomas, utilizando-se de estratégias para corrigir erros de treinamento, maus alinhamentos, flexibilidade diminuída, fraqueza muscular e o uso de equipamentos inadequados. Diminuir a intensidade, frequência e duração das atividades podem evitar danos adicionais. A terapia com uso de gelo pode controlar a dor e o edema, bem como reduzir o fluxo de sangue regional e as demandas metabólicas do tecido, ajudando assim, a prevenir danos adicionais (PAAVOLA et al., 2002).

Alongamento e fortalecimento do músculo tríceps sural são defendidos por diminuir a tensão no tendão calcâneo com o movimento normal. $\mathrm{O}$ treinamento excêntrico parece ser efetivo na diminuição da dor na tendinopatia do calcâneo, dando resultados promissores a curto prazo (três meses). Além da crioterapia e programas de alongamento 
e fortalecimento, muitas outras modalidades como calor, ultra-som, excitação elétrica e laser são comumente empregadas no tratamento da tendinopatia do calcâneo. Porém, evidências científicas a respeito da efetividade desses tratamentos são escassas e controversas (PAAVOLA et al., 2002).

Em 1984, Curwin e Stanish abriram caminho para o termo "treinamento excêntrico" como terapia para lesões tendíneas. Dessa base, Alfredson et al. fizeram algumas modificações. Primeiramente, eles consideraram que a dor faz parte do processo de recuperação e que, se o paciente não experimentasse nenhuma dor ao realizar o programa, carga deveria ser adicionada até provocá-la. Outra modificação era a inclusão de dois tipos de exercícios (Figura 1), um para o músculo sóleo ( $45^{\circ}$ de flexão de joelho) e outro para o gastrocnêmio (joelho estendido), realizados em três séries de 15 repetições duas vezes ao dia, resultando em um total de 180 contrações, num período de 12 semanas (BRUKNER; KHAN, 2006).

Figura 1 - Protocolo de Alfredson (1998). A. Gastrocnêmio. B. Sóleo $\left(45^{\circ}\right)$. Fonte: BRUKNER; KHAN (2006).
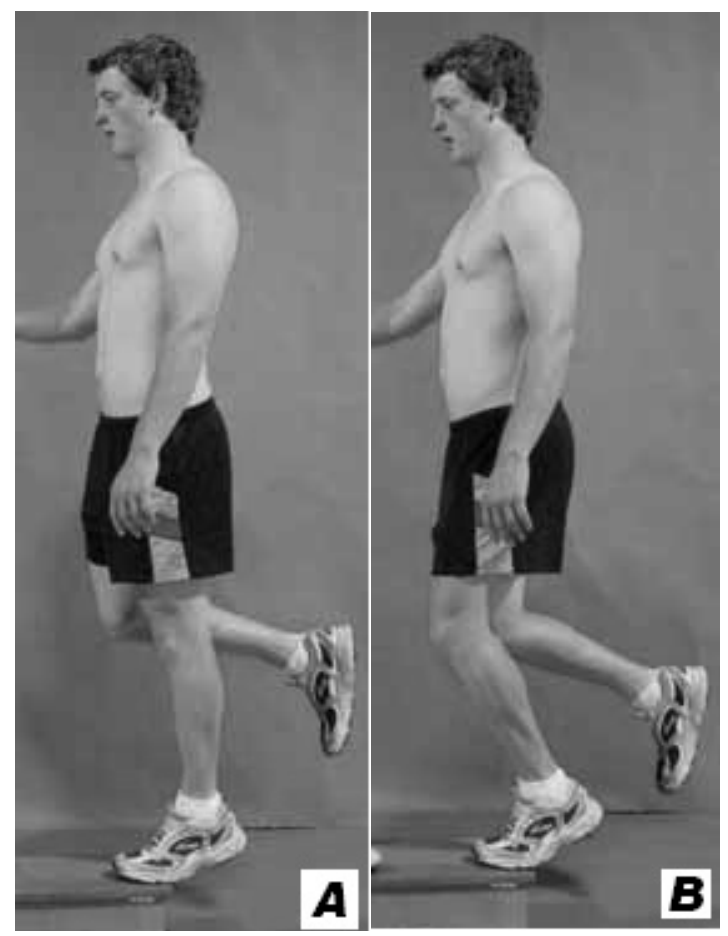

O treinamento excêntrico pode induzir uma resposta que normaliza as concentrações de glicosaminoglicanas e possivelmente melhora o arranjo das fibras, resultando em uma diminuição da densidade do tendão. Essa diminuição na densidade pode estar relacionada à interrupção do fluxo sanguíneo durante o exercício excêntrico nas áreas com neovascularização (OHBERG et al., 2004).

No estudo de Sayana e Maffulli (2007), que teve como objetivo verificar os efeitos do exercício excêntrico em pacientes sedentários com tendinopatia do calcâneo, 34 pacientes sedentários, com idade média de 51 anos, participaram de um programa progressivo de fortalecimento excêntrico dos músculos da panturrilha durante 12 semanas. Quinze pacientes (44\%) não melhoraram com o regime de exercício excêntrico.

Alfredson et al. (1998) informou uma redução significativa na dor e melhora da força em $100 \%$ $(n=15)$ dos pacientes com tendinopatia do calcâneo que participaram de um programa de exercícios envolvendo um lento e doloroso trabalho excêntrico. Todos esses pacientes participavam de jogos recreativos e voltaram ao nível prévio de atividade atlética.

Vários estudos demonstraram que o treinamento excêntrico do músculo gastrocnêmio pode ser um tratamento efetivo na tendinopatia não insersional do calcâneo. Fahlstrom et al. (2003) observaram que o treinamento excêntrico do músculo gastrocnêmio de 12 semanas conduziu a resultados satisfatórios em 90 dos 101 tendões calcâneos (89\%) com tendinopatia. Nesses pacientes, a quantidade de dor durante a atividade, registrada na escala analógica visual da dor, diminuiu significativamente de 6,7 para 1,0 .

Investigadores escandinavos demonstraram que um treinamento excêntrico com dor nos músculos tríceps sural dá excelentes resultados a curto prazo em até $89 \%$ dos pacientes com tendinopatia crônica do corpo do tendão calcâneo. Bons resultados clínicos estavam associados com diminuição da densidade do tendão e uma estrutura mais normal do tendão com nenhuma neovascularização restante (ALFREDSON, 2005).

Embora tratamentos cirúrgicos e excêntricos possam produzir melhora significativa em termos de dor e função, fica claro que só metade de todos os pacientes poderá retornar ao esporte dentro de 
um ano depois de tratamento com qualquer opção, sendo que um número ainda menor deles terá alívio de todos os sintomas. Assim, postula-se que o treinamento excêntrico deve ser indicado antes de qualquer procedimento cirúrgico, pois tratase de uma terapia de pouco risco e baixo custo (ALFREDSON et al., 1998).

\section{Conclusão}

Uma variedade de estudos vem demonstrando que a tendinopatia está relacionada a um processo degenerativo e não a um processo infamatório. Pesquisas demonstram rupturas na arquitetura normal das fibras colágenas, hiperplasia angiofibroblástica e aumento na matriz extracelular. As mudanças histológicas sugerem que tendinopatia seja uma tendinose em lugar de uma tendinite. Porém, alguns trabalhos não descartam a possibilidade de ter ocorrido uma resposta inflamatória aguda no tendão.

Devido ao grande número de estudos indicando a presença da tendinose, fica claro que o tratamento usual, com repouso, medicação anti-inflamatória e fisioterapia, deve ser revisto para uma maior possibilidade de recuperação. Mais estudos clínicos de outras modalidades de tratamento, além do treinamento excêntrico, devem ser feitos para avaliar sua efetividade frente a essa patologia.

\section{REFERÊNCIAS}

ALFREDSON H. The chronic painful Achilles and patellar tendon: research on basic biology and treatment. Scand J. Med. Sci. Sports, v.15, p.252-259, 2005.

ALFREDSON H.; PIETILA T.; JONSSON P.; LORENTZON R. Heavy-load eccentric calf muscle training for the treatment of chronic Achilles tendinosis. Am J Sports Med., v.26, p.360-366, 1998.

ALFREDSON H.; LORENTZON R. Chronic Achilles tendinosis. Recommendations for treatment and prevention. Sports Med.; v.29, n.2, p.135-146, 2000.

ALFREDSON H.; THORSEN K.; LORENTZON R. In situ microdialysis in tendon tissue: high levels of glutamate, but not prostaglandin E2 in chronic achilles tendon pain. Knee Surg Sports Traumatol Arthrosc., v.7, p.378-381, 1999.
ALFREDSON, H.; LJUNG, B. O.; THORSEN, K.; LORENTZON, R. In vivo investigation of ECRB tendons with microdialysis technique--no signs of inflammation but high amounts of glutamate in tennis elbow. Acta Orthop Scand., v.71, n.5, p.475-479, 2000.

AMATUZZI, M. M.; CARAZZATO, J. G. Medicina do esporte. São Paulo: Roca; 2004.

BAHR R.; FOSSAN B.; LOKEN S.; ENGEBRETSEN L. Surgical treatment compared with eccentric training fot patellar tendinopathy (jumper's knee). The Journal of Bone \& Joint Surgery, v.88, p.8, 2006.

BENEGAS E. Tratamento artroscópico da epicondilite lateral do cotovelo. Rev Bras Ortop.;; v.39, n.3, mar., 2004

BROWN R., ORCHARD J., KINCHINGTON M., HOOPER A., NALDER G. Aprotinin in the management of Achilles tendinopathy: a randomised controlled trial. Br J Sports Med.v.40, p.275-279, 2006.

BRUKNER P.; KHAN K. Clinical sports medicine. 3.ed. Austrália: McGraw-Hill; 2006.

ENWEMEKA, C. S. Inflammation, cellularity, and fibrillogenesis in regenerating tendon: implications for tendon rehabilitation. Phys Ther., v.69, n.10, 1989.

FAHLSTROM, M.; JONSSON, P.; LORENTZON, R.; ALFREDSON, H. Chronic achilles tendon pain treated with eccentric calf-muscle training. Knee Surg Sports Traumatol Arthrosc., v.11, p.327-333, 2003.

FILHO, G. R. M.; COHEN, M. T. Epicondilite lateral do cotovelo. R. Into., v.2, n.3, 5-12, 2004.

HALE, S. A. Etiology of patellar tendinopathy in athletes. J Sport Rehabil., v.14, 258-272, 2005.

JARDIM, M. Tendinopatia patelar. Essfisionline, set.; v.1, n.4, p.31-47, 2005.

JUNQUEIRA, L. C., CARNEIRO J. Histologia básica. Rio de Janeiro: Guanabara Koogan; 1990.

KHAN, K. M.; COOK, J. L.; TAUNTON, J. E.; BONAR, F. Overuse tendinosis, not tendinitis. Part 1: A new paradigm for a difficult clinical problem. The Physician and Sports Medicine, v.28, n.5, 2000.

KHAN, K. M.; COOK, J. L.; BONAR F., HARCOURT P., ASTROM M. Histopathology of common tendinopathies: update and implications for clinical management. Sports Med., v.27, n.6, p.393-408, 1999.

KHAN, K. M.; COOK, J. L. Overuse tendon injuries: where does the pain come from? Sport Medicine and Arthocopy Review, v.8, n.1, 2000.

LEON, N. R. Tendências atuais no tratamento das tendinopatias. Disponível em: www.terapiamanual.com.br. Acesso em 1 de dezembro de 2006. 
LIAN, Ö.; DAHL, J.; ACKERMANN, P. W.; FRIHAGEN, F.; ENGEBRETSEN, L.; BAHR, R. pronociceptive and antinociceptive neuromediators in patellar tendinopathy. The American Journal of Sports Medicin., v.34, n. 11, 2006.

MAFFULLI, N.; BENAZZO, F. Basic science of tendons. Sports Medicine and Artroscopy Review., v.8, n.1, p.1-5, 2000.

NORDIN, M.; FRANKEL, V. H. Biomecânica básica do sistema musculoesquelético. 3.ed. Rio de Janeiro: Guanabara Koogan, 2003.

ÖHBERG, L.; LORENTZON, R.; ALFREDSON, H. Eccentric training in patients with chronic achilles tendinosis: normalised tendon structure and decreased thickness at follow up. Br J Sports Med., v.38, p.8-11, 2004.

PAAVOLA, M.; KANNUS, P.; JARVINEM, T. A. H.; KHAN, K.; JOZSA, L.; JARVINEM, M. Achilles tendinopathy. J Bone Joint Surg Am., v.84, p.2062-2076, 2002.

RILEY, G. The pathogenesis of tendinopathy. A molecular perspective. Rheumatology, v.43, p.131-142, 2004.

SAYANA, M. K.; MAFFULLI, N. Eccentric calf muscle training in non-athletic patients with Achilles tendinopathy. Journal of Science and Medicine in Sport, v.10, p.52-58, 2007.

SHARMA, P., MAFFULLI, N. Tendon Injury and tendinopathy: healing and repair. J Bone Joint Surg Am., v.87: 187-202. 2005

WHITING, W.; ZERNICKE, R. F. Biomecânica da lesão musculoesquelética. Rio de Janeiro: Guanabara Koogan; 2001 